\title{
The Effect of Pulmonary Sarcoidosis on Cardiac Autonomic Dysfunction
}

\author{
Akciğer Tutulumu Olan Sarkoidozun Kardiyak Otonom Disfonksiyon Üzerine Etkisi
}

\author{
(D) Ali MANAV1, (D) Gökay TAYLAN², (D) Meryem AKTOZ² \\ ${ }_{1}^{1}$ üleburgaz State Hospital, Clinic of Cardiology, Kırklareli, Turkey \\ ${ }^{2}$ Trakya University Faculty of Medicine, Department of Cardiology, Edirne, Turkey
}

\begin{abstract}
Aim: The assessment of heart rate variability (HRV) has been considered as an important non-invasive method to evaluate cardiac autonomic function. Concerning recent evidence on the relationship between impaired autonomic dysfunction and sarcoidosis, we aimed to investigate the effect of pulmonary sarcoidosis on cardiac autonomic dysfunction.

Materials and Methods: This prospective study comprised of 36 participants, including 18 patients diagnosed with pulmonary sarcoidosis and 18 age-matched healthy volunteers. All participants underwent echocardiographic examination, 12-channel electrocardiography and 24-h Holter monitoring. HRV parameters were determined and compared between the groups.

Results: In time domain analyses, RMSDD values significantly decreased in the patient group compared to the control group ( $p=0.043$ ). The low-frequency power in frequency domain analyses between sarcoidosis patients and controls demonstrated a statistically significant difference $(p=0.045)$. In the correlation analysis, PR duration was negatively correlated with all-time domain and frequency domain parameters as SDNN, SDANN and high-frequency values, which had a statistically significant difference ( $p=0.009, p=0.003, p=0.047$ respectively). Corrected QT (QTc) duration was negatively correlated with all-time domain and frequency domain parameters as well. The low-frequency/high-frequency ratio was positively correlated with QTc duration.

Conclusion: The patients with pulmonary sarcoidosis displayed a decrease in all HRV values reflecting diminished parasympathetic tone or blunted cardiac response to vagal modulation. This may cause cardiac outcomes such as atrioventricular conduction abnormalities, proarrhythmic tendency, ventricular arrhythmias and sudden death.
\end{abstract}

Keywords: Heart rate variability, sarcoidosis, autonomic dysfunction

\section{ÖZ}

Amaç: Kalp hızı değişkenliği (KHD), kardiyak otonom fonksiyonun değerlendirilmesinde kullanılan non-invaziv bir yöntemdir. Çalışmamızda akciğer tutulumu olan sarkoidoz hastalarında KHD ölçüm sonuçları değerlendirilerek, kardiyak otonom fonksiyon üzerine etkisinin araştırılması amaçlanmışıır.

Gereç ve Yöntem: Çalışmaya 18 akciğer tutulumlu sarkoidoz hastası ile yaş ve cinsiyet uyumlu 18 sağlıklı gönüllü bireyden oluşan kontrol grubu olmak üzere toplamda 36 kişi dahil edildi. Tüm hastalara transtorasik ekokardiyografi, elektrokardiyografi (EKG) ve 24-saat EKG Holter uygulandı. Holterde saptanan KHD parametreleri kullanılarak gruplar karşılaştıııldı.

Bulgular: Zaman alan analizinde RMSDD ölçüm değerleri ve frekans alan analizinde düşük frekans değerleri sarkoidoz grubunda kontrol grubuna kıyasla anlamlı ölçüde düşük bulundu ( $p=0,043$ ve $p=0,045)$. Ayrıca korelasyon analizinde, PR süresi ile zaman alan parametrelerinden SDNN ve SDANN, frekans alan parametrelerinden yüksek frekans arasında istatistiksel olarak anlamlı negatif bir korelasyon saptandı $(p=0,009, p=0,003$, $p=0,047$ sırasıyla). Düşük frekans/yüksek frekans oranı, düzeltilmiş QT süresi ile pozitif korelasyon gösterdi.

Address for Correspondence: Ali MANAV MD, Lüleburgaz State Hospital, Clinic of Cardiology, Kırklareli, Turkey

Phone: +90 5326249297 E-mail: alimanav73@gmail.com ORCID ID: orcid.org/0000-0003-1071-2872

Received: 30.04.2021 Accepted: 26.08.2021

๑Copyright 2021 by the Tekirdağ Namık Kemal University Faculty of Medicine / Namık Kemal Medical Journal published by Galenos Publishing House. 
Sonuç: Akciğer tutulumlu sarkoidoz hastalarında KHD parametrelerinde saptanan değişiklikler, azalmış parasempatik tonus ve vagal düzenlemeye bozulmuş kardiyak yanıt ile ilişkili olup, bu durum kardiyak aritmilere yatkınlık, ani kardiyak ölüm ve atriyoventiküler iletim bozukluğuna sebep olabilir.

Anahtar Kelimeler: Kalp hızı değişkenliği, sarkoidoz, otonom disfonksiyon

\section{INTRODUCTION}

Sarcoidosis is a chronic systemic disease of unknown cause characterized by the presence of noncaseating granulomas'. Although the lung and the lymphatic system are the most commonly involved, it affects multiple body systems and frequently young and middle-aged adults ${ }^{2}$. Clinical cardiac sarcoidosis can manifest with ventricular arrhythmias, conduction abnormalities, heart failure, and sudden death $^{3}$. Heart rate $(H R)$ varies as a result of respiration, thermoregulation, blood pressure regulation, the reninangiotensin system, circadian rhythms, and other factors ${ }^{4}$. Also, the intervals of each heart beats depend on some unique physiologic mechanisms which are altered by the autonomic nervous system (ANS) via efferent vagal and sympathetic nerve impulses 5 .

Dysfunction of the ANS is highly associated with increased risk of mortality in individuals with diabetes, heart failure, after myocardial infarction and in some systemic diseases ${ }^{6-9}$. Deterioration of autonomic function in the presence of cardiovascular disease has been strongly implicated in the pathophysiology of arrhythmogenesis and sudden cardiac death which have been associated with an adverse prognosis ${ }^{10}$.

The assessment of cardiac autonomic function is carried out by the evaluation of HR variability (HRV) which has been considered as an important non-invasive method. This method supplies indirect information about cardiac autonomic modulation with oscillation in the interval between consecutive heart beats resulting from rhythmic changes in sympathetic and parasympathetic activity ${ }^{11,12}$.

A high variability in $\mathrm{HR}$ suggests good adaptability, indicating a healthy individual with well-functioning autonomic control mechanism. Inversely a low variability is usually a sign of abnormal and insufficient adaptability of the ANS and it implies the presence of a physiological malfunctioning ${ }^{13}$.

Little is known about autonomic dysfunction in patients with pulmonary sarcoidosis. The aim of this study was to evaluate HRV as a tool to assess cardiovascular ANS function in patients with pulmonary sarcoidosis patients.

\section{MATERIALS AND METHODS}

\section{Patients}

This prospective study includes the patient group diagnosed with pulmonary sarcoidosis at the clinic of chest disease with clinical and histological diagnosis. 24-h Holter monitoring, 12-channel electrocardiography (ECG), echocardiographic (ECHO) examination, blood sample analysis and baseline examination were carried out at the cardiology outpatient clinic. Patients who had preexisting medical diagnoses such as ischemic heart disease, significant valvular abnormalities, heart failure or cardiomyopathy, diabetes, renal failure, cerebrovascular disease, thyroid disease, atrio-ventricular node conduction abnormality, and cardiac pacemaker implantation history, or those who were receiving any medication that might interfere with autonomic regulation were also excluded. None of these patients had been previously diagnosed with cardiac sarcoidosis. The final patient group included 18 patients, and the control group consisted of 18 healthy volunteers. Written informed consent was obtained from each patient following a detailed explanation of the objectives and protocol. The study was conducted in accordance with the ethical principles stated in the Declaration of Helsinki and approved by the Trakya University of Scientific Research Ethics Committee (protocol number: 2016/258, date: 23.11.2016).

\section{Analysis of Heart Rate Variability}

Patients underwent 24-h ECG monitoring using a threechannel DMS Holter Recorder (DM Systems Co. LTD., Beijing/ China). The recording speed was $2 \mathrm{~mm} / \mathrm{s}$ and the sampling rate was $300 \mathrm{~Hz}$. A preliminary analysis allowed the exclusion of noise, artefacts, premature beats, or post extrasystolic pauses from further analysis. All tapes were subsequently analyzed to measure HRV using a validated CardioScan HRV program (version 11.5, DM Software Inc.). Only those ECG recordings that met the standards proposed by the task force of the European Society of Cardiology and the North American Society of Pacing and Electrophysiology as acceptable for HRV interpretation were analyzed. The program calculates the mean QT interval, which is the time from the start of the 0 wave to the end of the T wave. The end of the T wave was defined as the point of maximal change in the slope as the T wave merged with the baseline. OT interval was corrected for heart rate by calculating OTc. OTc was calculated with the Bazett's equation [QTc $=$ QT interval (ms) $/ \sqrt{ }(60 /$ heart rate)]. Also, holter program calculates the mean PR interval, which is the time from the onset of the $\mathrm{P}$ wave to the start of the QRs complex.

\section{Time Domain Analysis}

The mean RR (mean of all normal RR intervals) duration from the whole recording and the following time domain measures 
of HRV were calculated: standard deviation of all normal RR intervals (SDNN), standard deviation of the averages of RR intervals in all 5 min segments (SDANN), root-mean square of difference of successive RR intervals (RMSSD), percentage of adjacent normal RR intervals $>50$ ms different (pNN50).

\section{Spectral Analysis}

Spectral measures were computed using the fast-Fourier transform (FFT) method. Spectral plots allowed the identification of the total oscillatory power of 0.01 to $1.0 \mathrm{~Hz}$ as well as two subsets of the frequency domain: low-frequency (LF) (0.04-0.15 Hz) and high-frequency (HF) $(0.15$ to $0.40 \mathrm{~Hz})$.

\section{Echocardiography}

Transthoracic ECHO was performed by one of the authors, who was blinded to the patient's clinical data, using a GE Vingmed ultrasound system VII (GE Healthcare, Horten, Norway) with a 2-4 $\mathrm{MHz}$ phased array transducer. Recordings were taken from patients positioned in standard $\mathrm{ECHO}$ positions, under ECG monitoring, according to the suggestions of the American Society of Echocardiography. Left ventricular ejection fraction (EF) was measured using the modified Simpson method. Left ventricle diastolic function parameters were measured by pulsed-wave Doppler-derived transmitral inflow velocities obtained in the apical 4-chamber view, with the sample volume placed at the mitral valve leaflet tips. Measurements included the trans-mitral early diastolic rapid filling (E-wave) and atrial contraction late filling (A-wave) velocities to calculate E/A ratio. The tricuspid annular plane systolic excursion (TAPSE) was obtained from the apical four-chamber view with the M mode.

\section{Statistical Analyses}

A statistical analysis was performed using the Statistical Package for the Social Sciences (SPSS) software (version 17.0, SPSS Inc., Chicago, IL, USA). Continuous variables were expressed as means \pm standard deviation (SD) and medians (minimum-maximum). Continuous variables were compared using the independent samples t-test or Mann-Whitney $\mathrm{U}$ test. Correlations between ECG measures and parameters of time and spectral analysis of HRV were computed by the Spearman's correlation coefficient.

\section{RESULTS}

While 18 sarcoidosis patients studied (11 females, 7 males) had a mean age of $55.9( \pm 8.6 \mathrm{SD})$ years, 18 control subjects (11 females, 7 males) had a mean age of 52.3 ( \pm 14.8 SD) years. The age difference between the groups did not reach a statistical significance ( $p=0.367$ ) (Table 1$)$. The ECHO values between the patient and control groups were compared; $\mathrm{EF} \%$ was lower in the patient group than in the control group, but not statistically significant ( $p>0.05$ ). Inversion of the E/A ratio at pulsed Doppler examination of mitral flow (an index of diastolic dysfunction) was noted in 15 patients whereas it was obtained in 6 individuals of the control group $(p=0.007)$. Although LV end-systolic diameter was greater but not statistically significant in the patient group ( $p>0.05)$, LV end-diastolic diameter was significantly greater in the same group $(65.1 \pm 21.7$ vs. $45.8 \pm 3.9 ; p=0.001)$. TAPSE was lower in the sarcoidosis group than in the control subjects. It was statistically significant $(21.1 \pm 3.1$ vs $23.2 \pm 2.9$ for controls; 0.032) (Table 1).

The HRV analysis revealed a remarkable reduction in all time domain and frequency domain HRV parameters compared to the control subjects. In the time domain analyses, as SDNN, SDANN and pNN50 values were lower in the patient group than in the control group. They were not statistically significant (all $p>0.05$ ) whereas RMSDD values significantly decreased in the patient group compared to the control group (18.3 \pm 4.4 vs. $26.9 \pm 13.5$ for controls; $p=0.043$ ).

In the frequency domain analyses, comparison of the LF power between sarcoidosis patients and controls demonstrated a

Table 1. Baseline demographic and echocardiographic parameters of the study population

\begin{tabular}{|c|c|c|c|c|c|}
\hline \multirow{3}{*}{ Sex, M/F } & \multicolumn{2}{|c|}{ Patient $(n=18)$} & \multicolumn{2}{|c|}{ Control $(n=18)$} & \multirow{2}{*}{$p$} \\
\hline & Mean $\pm S D$ & Median (min-max) & Mean $\pm S D$ & Median (min-max) & \\
\hline & \multicolumn{2}{|l|}{$7 / 11$} & \multicolumn{2}{|l|}{$7 / 11$} & 1.000 \\
\hline BMI $\left(\mathrm{kg} / \mathrm{m}^{2}\right)$ & $26.0 \pm 2.4$ & $25.9(22.9-30.1)$ & $26.1 \pm 4.3$ & $26.2(18.2-33)$ & 0.658 \\
\hline EF $(\%)$ & $64.2 \pm 4.8$ & $64(55-71)$ & $65.6 \pm 4.2$ & 65.5 (59-75) & 0.417 \\
\hline TAPSE $(\mathrm{mm})$ & $21.1 \pm 3.1$ & $20(15-26)$ & $23.2 \pm 2.9$ & $23(17-28)$ & 0.032 \\
\hline E/A, type 1 DD & \multicolumn{2}{|l|}{$15 / 3$} & \multicolumn{2}{|l|}{$6 / 12$} & 0.007 \\
\hline
\end{tabular}


statistically significant difference $(18.1 \pm 5.0$ vs $22.6 \pm 5.7$ for controls; $p=0.045)$. HF component in the sarcoidosis patients decreased but did not differ significantly ( $p>0.05)$. Also, the LF/ $\mathrm{HF}$ ratio was slightly increased but there was not a statistically significant difference ( $p>0.05)$. The mean heart rate during 24-hour Holter monitorization in the patient group was lower than in the control group ( $p>0.05)$ (Table 2).

In the correlation analysis, PR duration was negatively correlated with all-time domain and frequency domain parameters. In addition, SDNN, SDANN and HF values had statistically significant differences $(p=0.009, p=0.003, p=0.047$ respectively). Besides, the LF/HF ratio was positively correlated with PR duration but there was no significant difference ( $p>0.05)$. OTc duration was negatively correlated with alltime domain and frequency domain parameters as well. The
LF/HF ratio was positively correlated with OTc duration. All correlations with HRV and OTc duration were not statistically significant ( $p>0.05$ ) (Table 3).

\section{DISCUSSION}

Non-invasive assessment of autonomic system by measuring HRV gives clinically and prognostically useful information in some cardiac and systemic diseases. Alterations in the HRV have been shown to be a strong and independent predictor of post-infarction mortality and to have prognostic significance in patients with heart failure and in patients with diabetic autonomic neuropathy $y^{7,8,14}$. Therefore, methods for assessing ANS and its modulation are very important to prevent undesired cardiovascular events in cardiac patients as well as in non-cardiac patients.

\section{Table 2. Comparison of the heart rate variability indices between the patient and control groups}

\begin{tabular}{|c|c|c|c|c|c|}
\hline & Patient $(n=$ & & Control $(n=$ & & \\
\hline & Mean $\pm S D$ & Median (min-max) & Mean $\pm S D$ & Median (min-max) & $p$ \\
\hline SDANN (ms) & $101.1 \pm 25.2$ & $96.5(66-159)$ & $102.2 \pm 31.4$ & $101.5(49-176)$ & 0.740 \\
\hline RMSDD (ms) & $18.3 \pm 4.4$ & $19(11-25)$ & $26.9 \pm 13.5$ & $21.5(12-58)$ & 0.043 \\
\hline pNN50 (\%) & $2.1 \pm 1.4$ & $2(0-4)$ & $6.0 \pm 8.3$ & $2.5(0-35)$ & 0.150 \\
\hline $\mathrm{LF} / \mathrm{HF}$ & $3.9 \pm 2.9$ & $3.5(0.9-14)$ & $3.7 \pm 1.9$ & $3.5(0.9-7.3)$ & 0.899 \\
\hline Mean HR (rate/minute) & $76.6 \pm 9.8$ & $74.5(60-94)$ & $78.3 \pm 9.5$ & 75 (64-93) & 0.924 \\
\hline
\end{tabular}

SDANN: Standard deviation of the averages of RR intervals in all 5 min segments, SDNN: Standard deviation of all normal RR intervals, RMSSD: Root-mean square of difference of successive RR intervals, pNN50: Percentage of adjacent normal RR intervals > 50 ms different, LF: Low frequency, HF: High frequency, LF/HF: The ratio of low frequency to high frequency, HR: Heart rate, min-max: Minimum-maximum, SD: Standard deviation

Table 3. The correlation analysis between heart rate variability and electrocardiographic indices in study population

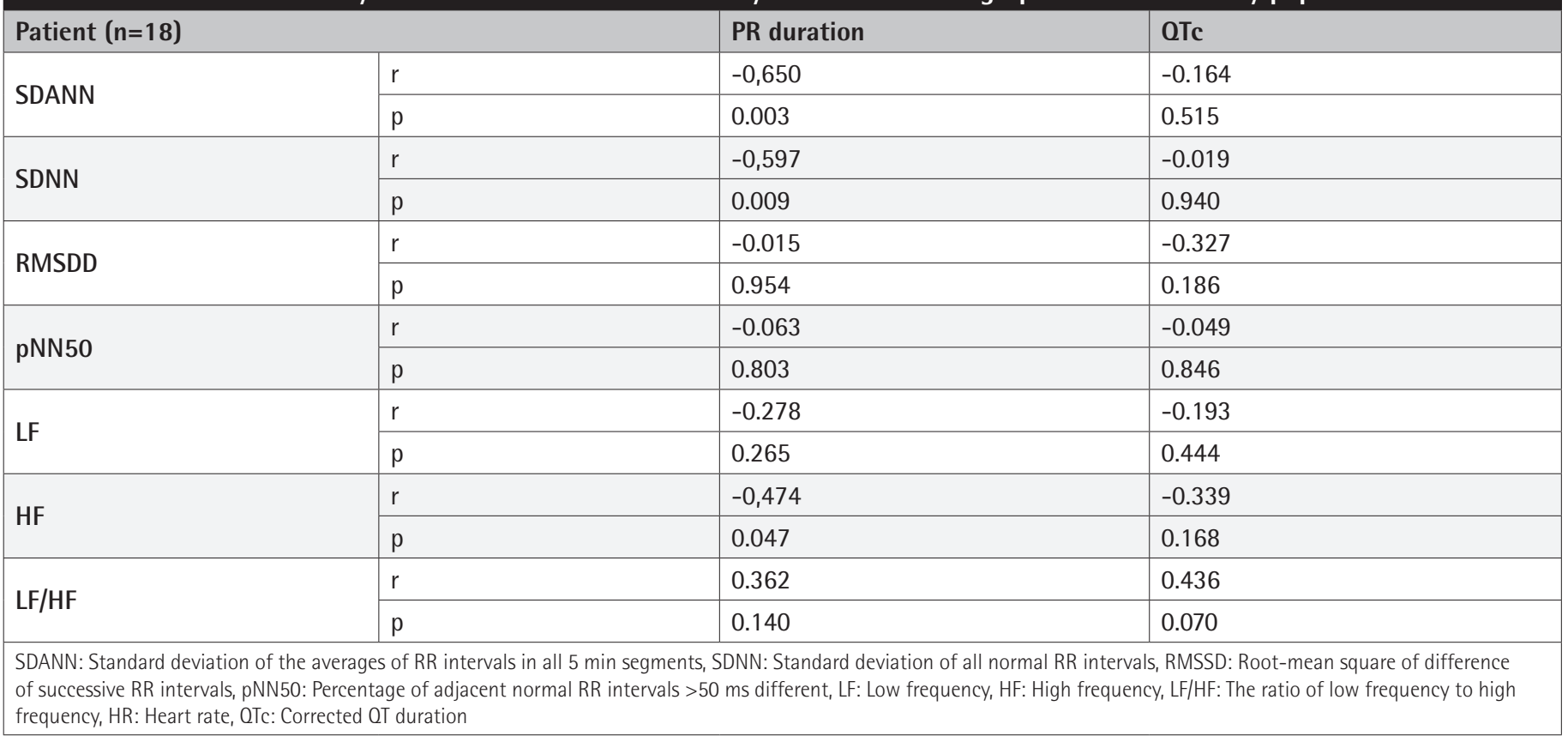


HRV can be assessed with a number of methods. The most commonly used are frequency domain and time domain analyses. In these methods, measures are based on the analysis of the time intervals between each successive normal QRs complex which are determined from a routine 24-hour ambulatory ECG ${ }^{4}$.

SDNN is the most commonly used time domain HRV parameter that measures the standard deviation of all normal RR (NN) intervals during a 24-hour period. SDNN is considered as all the components responsible for variability in the entire period of recording". The most commonly used variables derived from differences between normal R-R intervals are RMSSD, pNN50 and NN50 $0^{15}$. These measures evaluate parasympathetic modulation of normal $R-R$ intervals driven by ventilation in the existence of normal sinus rhythm and AV-nodal function ${ }^{4,11,16}$.

Frequency-domain methods separate to signals of the heart rate according to frequency and density. FFT or autoregressive modeling can be used to separate HRV into four main spectral bands; very LF band, LF band and HF band and ultra-LF"1.

$\mathrm{HF}$ is in a range from 0.15 to $0.4 \mathrm{~Hz}$. The normal respiratory rate is within the HF band that reflects parasympathetic or vagal activity, and therefore, this band is frequently called the respiratory band because it corresponds to the heart rate (HR) variations related to the respiratory cycle ${ }^{16}$. These HR changes are known to be respiratory sinus arrhythmia ${ }^{11,16}$.

LF power, which is modified by both the sympathetic and parasympathetic nervous systems and greatly affected by the baroreceptor system, has bandwidth from 0.04 to $0.15 \mathrm{~Hz}^{4,17}$. By some authors, the absolute and normalized LF powers have been considered as an index of sympathetic modulation of the heart rate and the ratio of LF to HF power has been used as an assessment of the balance between sympathetic and parasympathetic activities, which is called sympathovagal balance ${ }^{14,18}$.

In the present study, we found that all-time domain parameters were decreased. Although they were not statistically significant except RMSSD, it might be evaluated as a deterioration of sympathovagal balance. RMSSD reflects parasympathetic modulation driven by ventilation; therefore, altered respiratory performance and reduced parasympathetic activity over the heart could cause a statistically significant decrease in RMSSD.

In the study designed by Aktop et al. ${ }^{19}, 31$ pulmonary sarcoidosis patients were examined for daytime and night-time HRV parameters separately also during 24 hours. They found that 24-h SDNN values decreased in all time periods. In the study by Uslu et al. ${ }^{20}$, the observed SDNN values decreased in noncardiac sarcoidosis patients who were compared to controls. They interpreted these findings as a reduction of vagal activity with a concomitant sympathetic dominance.
Furthermore, the frequency parameters as LF and HF during 24-h, which were studied by Aktop et al. ${ }^{19}$, were significantly lower when compared to the control group. Additionally, they observed that 24-h LF/HF ratios slightly increased but it was not statistically significant. These results were parallel when compared to our study. In our study, the patients with sarcoidosis had decreased HRV in the HF and LF components upon spectral analysis compared to healthy controls. Regarding $\mathrm{LF}$, there was a statistically significant difference. It might be interpreted as reduced vagal control over the heart and shift of sympathovagal balance toward the sympathetic dominance.

Also, our results indicated 24-h LF/HF ratios that were slightly increased but not statistically significant. In the same manner, Tiran et al. ${ }^{21}$ studied with 12 sarcoidosis patients and 12 healthy control subjects whose mean values for HRV in the HF domain were significantly reduced. This result was interpreted that the patients with sarcoidosis revealed decreased HRV in the HF component, possibly reflecting decreased parasympathetic tone and cardiac response to vagal modulation. In the same study, they found increased ratio of LF to HF power (LF/HF) in sarcoidosis patients. In the light of these findings, it could be argued that increased LF/HF ratios in sarcoidosis patients reflect an altered sympathovagal balance.

In the study of Hsiao et al. ${ }^{22}$, fifteen AV block patients before and after temporary $\mathrm{WI}$ pacemaker and 15 subjects with normal AV conduction were investigated by using an esophageal lead to detect PP intervals for the analysis of HRV with time domain as SDNN, pNN50 and RMSSD which were decreased significantly in patients with AV block. The LF/HF ratio was increased in patients with $\mathrm{AV}$ block and remained increased after insertion of a temporary ventricular inhibited pacemaker $(\mathrm{VI})$, whereas the time domain parameters were normalized after $\mathrm{WI}$ insertion. In our study, we found that all-time domain and frequency domain parameters were negatively correlated with PR duration. SDNN and SDANN as the time domain values and $\mathrm{HF}$ as the frequency domain value were statistically significant. Also, the LF/HF ratio was found positively correlated in the present study. It could be assessed as decreased parasympathetic tonus and altered sympathovagal balance might delay AV conduction in sarcoidosis patients.

In the light of findings, decreased HRV may contribute to any degree of atrioventricular block, malign arrhythmia and sudden death. It may help to clinician in the course of deciding on the time and type of the therapy.

\section{Study Limitations}

Potential limitations of the present study might be the relatively small sample size, and thus the number of participating centers should be increased and the results should be confirmed with more comprehensive studies. 


\section{CONCLUSION}

In conclusion, our data seem to indicate that HRV may be a noninvasive, inexpensive and efficient modality to evaluate autonomic dysfunction and also contribute to prognosis in pulmonary sarcoidosis patients.

\section{Ethics}

Ethics Committee Approval: The study were approved by the Trakya University of Scientific Research Ethics Committee (protocol number: 2016/258, date: 23.11.2016).

Informed Consent: Consent form was filled out by all participants.

Peer-review: Externally peer-reviewed.

\section{Authorship Contributions}

Surgical and Medical Practices: A.M., G.T., M.A., Concept: A.M., G.T., M.A., Design: A.M., G.T., M.A., Data Collection or Processing: A.M., G.T., Analysis or Interpretation: A.M., M.A., Literature Search: A.M., G.T., M.A., Writing: A.M., G.T., M.A.

Conflict of Interest: No conflict of interest was declared by the authors.

Financial Disclosure: The authors declared that this study received no financial support.

\section{References}

1. Ogedengbe JO, Adelaiye AB, Kolawole OV. Effects of exercise on PR intervals, QRS durations and QTC intervals in male and female students of University of Abuja. J Pak Med Assoc. 2012;62:273-5.

2. Iannuzzi MC, Rybicki BA, Teirstein AS. Sarcoidosis. N Engl J Med. 2007;357:2153-65.

3. Gilotra N, Okada D, Sharma A, Chrispin J. Management of Cardiac Sarcoidosis in 2020. Arrhythm Electrophysiol Rev. 2020;9:182-8.

4. McCraty R, Shaffer F. Heart Rate Variability: New Perspectives on Physiological Mechanisms, Assessment of Self-regulatory Capacity, and Health risk. Glob Adv Health Med. 2015;4:46-61.

5. Hainsworth R. Physiology of the Cardiac Autonomic System, in Clinical Guide to Cardiac Autonomic Tests, M. Malik (eds). Dordrecht: Springer; 1998:p.3-28.

6. Vinik Al, Casellini C, Parson HK, Colberg SR, Nevoret ML. Cardiac Autonomic Neuropathy in Diabetes: A Predictor of Cardiometabolic Events. Front Neurosci. 2018;12:591.
7. Nolan J, Batin PD, Andrews R, Lindsay SJ, Brooksby $\mathrm{P}$, Mullen $\mathrm{M}$, et al. Prospective study of heart rate variability and mortality in chronic heart failure: results of the United Kingdom heart failure evaluation and assessment of risk trial (UK-heart). Circulation. 1998:98:1510-6.

8. Huikuri HV, Stein PK. Clinical application of heart rate variability after acute myocardial infarction. Front Physiol. 2012;3:41.

9. Ferri $C$, Emdin $M$, Giuggioli D, Carpeggiani $C$, Maielli $M$, Varga $A$, et al. Autonomic dysfunction in systemic sclerosis: time and frequency domain 24 hour heart rate variability analysis. Br J Rheumatol. 1997;36:669-76.

10. Lombardi F, Mäkikallio TH, Myerburg RJ, Huikuri HV. Sudden cardiac death: role of heart rate variability to identify patients at risk. Cardiovasc Res. 2001;50:210-7.

11. Heart rate variability: standards of measurement, physiological interpretation and clinical use. Task Force of the European Society of Cardiology and the North American Society of Pacing and Electrophysiology. Circulation. 1996;93:1043-65.

12. Lahiri MK, Kannankeril PJ, Goldberger JJ. Assessment of autonomic function in cardiovascular disease: physiological basis and prognostic implications. J Am Coll Cardiol. 2008;51:1725-33.

13. Pumprla J, Howorka K, Groves D, Chester M, Nolan J. Functional assessment of heart rate variability: physiological basis and practical applications. Int J Cardiol. 2002;84:1-14.

14. Ewing DJ, Campbell IW, Clarke BF. The natural history of diabetic autonomic neuropathy. Q J Med. 1980;49:95-108.

15. Li K, Rüdiger H, Ziemssen T. Spectral Analysis of Heart Rate Variability: Time Window Matters. Front Neurol. 2019;10:545.

16. Shaffer F, McCraty R, Zerr CL. A healthy heart is not a metronome: an integrative review of the heart's anatomy and heart rate variability. Front Psychol. 2014;5:1040.

17. Houle MS, Billman GE. Low-frequency component of the heart rate variability spectrum: a poor marker of sympathetic activity. Am J Physiol. 1999;276:H215-23.

18. Malliani A, Pagani M, Lombardi F, Cerutti S. Cardiovascular neural regulation explored in the frequency domain. Circulation. 1991;84:482-92.

19. Aktop Z, Tanrıverdi H, Uygur F, İşleyen A, Kalaycı B, Gursoy YC, et al. Diurnal characteristics of heart rate variability in patients with sarcoidosis. Herz. 2017;42:498-504.

20. Uslu N, Akyol A, Gorgulu S, Eren M, Ocakli B, Celik S, et al. Heart rate variability in patients with systemic sarcoidosis. Ann Noninvasive Electrocardiol. 2006;11:38-42.

21. Tiran B, Heller I, Isakov A, Barnea O, Greif J, Topilsky M. Heart rate variability in sarcoidosis: a frequency domain analysis. Eur J Intern Med. 2004;15:51822.

22. Hsiao HC, Chiu HW, Lee SC, Kao T, Chang HY, Kong CW. Esophageal PP intervals for analysis of short-term heart rate variability in patients with atrioventricular block before and after insertion of a temporary ventricular inhibited pacemaker. Int J Cardiol. 1998;64:271-6. 